Revue de l'Institut des langues et cultures

d'Europe, Amérique, Afrique, Asie et Australie

$25 \mid 2016$

De la bibliothèque intérieure à la bibliothèque collective : livres et lectures en Espagne (XVI $\mathrm{I}^{\mathrm{e}} \mathrm{XX \textrm {I } ^ { \mathrm { e } }}$ siècles)

\title{
Hombres públicos, bibliotecas privadas: los casos del pintor toledano Domenico Theotocópuli y del ilustrado Francisco Cerdá y Rico
}

Hommes publics, bibliothèques privées : les cas du peintre tolédan, Domenikos Theotokopoulos, et de l'auteur éclairé, Francisco Cerdá y Rico

Public Men, Private Libraries, the Example of Toledian Painter Domeniko Theotocópoulos and Enlightened Figure Francisco Cerdá y Rico

\section{Valérie Molero}

\section{OpenEdition}

Journals

Edición electrónica

URL: http://journals.openedition.org/ilcea/3801

DOI: 10.4000/ilcea.3801

ISSN: 2101-0609

\section{Editor}

UGA Éditions/Université Grenoble Alpes

\section{Edición impresa}

ISBN: 978-2-84310-322-3

ISSN: 1639-6073

\section{Referencia electrónica}

Valérie Molero, «Hombres públicos, bibliotecas privadas: los casos del pintor toledano Domenico Theotocópuli y del ilustrado Francisco Cerdá y Rico », ILCEA [En línea], 25 | 2016, Publicado el 31 enero 2016, consultado el 30 abril 2019. URL : http://journals.openedition.org/ilcea/3801 ; DOI : 10.4000/ ilcea.3801

Este documento fue generado automáticamente el 30 abril 2019.

(C) ILCEA 


\title{
Hombres públicos, bibliotecas privadas: los casos del pintor toledano Domenico Theotocópuli y del ilustrado Francisco Cerdá y Rico
}

\author{
Hommes publics, bibliothèques privées : les cas du peintre tolédan, Domenikos \\ Theotokopoulos, et de l'auteur éclairé, Francisco Cerdá y Rico \\ Public Men, Private Libraries, the Example of Toledian Painter Domeniko \\ Theotocópoulos and Enlightened Figure Francisco Cerdá y Rico
}

Valérie Molero

1 Los efectos finales sobre la cultura, la educación, las libertades públicas y, en general, sobre tantos campos relacionados con las ciencias sociales y políticas, que la Ilustración trasladó a la vida de los pueblos y las sociedades, han sido estudiados a lo largo de todos los tiempos por numerosos investigadores. El espíritu ilustrado proyectó su influencia sobre las nuevas formas de pensamiento buscando espacios diferentes de conciliación social. Fijó otros códigos relacionados con la vida de las naciones, los derechos de los individuos y el espíritu de las leyes. Todo ello envuelto en un moderado manto de impulso democrático en el que los derechos y libertades desempeñaban un papel preponderante.

2 Todo el siglo xviII es un tiempo propicio para analizar esta nueva realidad en muchos países europeos mientras se experimentan en ellos las primeras turbulencias formales de lo que podríamos denominar «crisis de poderes», o, lo que es lo mismo, la búsqueda de un equilibrio actualizado entre la Iglesia, el Estado y la sociedad civil como instituciones más sobresalientes. El caso español ofrece numerosas ocasiones donde esta pugna se visualiza de manera especial, a través de unos problemas vinculados a las políticas absolutistas de los monarcas de la época y al sentimiento dogmático emanado de la curia vaticana.

3 En medio de este panorama, un nuevo hecho que ya había tenido sus antecedentes en los dos siglos anteriores viene a modificar profundamente uno de los aspectos básicos de la 
sociedad que se relaciona con la implantación y extensión de la cultura escrita. Nos referimos a la aparición de la imprenta y, progresivamente, la edición de libros.

Este acontecimiento tuvo una incidencia directa sobre la implantación de la lectura entre las masas analfabetas, convulsionando las formas de conocimiento y elevando el nivel cultural de determinados sectores. Estaba naciendo un nuevo capítulo en la culturización de los ciudadanos. A su vez, la difusión de los libros se multiplicó de forma incesante en muchos países, provocando la aparición de lugares específicos para su mantenimiento y custodia. Surgieron así espacios concretos - las bibliotecas- destinadas a albergar esta modalidad de cultura escrita que fue la base para la extensión de la lectura, la catalogación y estudio de las obras, y la organización y administración de los servicios. No pasaría mucho tiempo sin que todas estas actividades y otras más se fueran profesionalizando dando paso a la aparición muchas décadas después, de una nueva ciencia, la biblioteconomía, y una nueva profesión, el bibliotecario.

\section{Las caras ocultas de las bibliotecas}

5 Editar un libro, comprarlo, venderlo o coleccionarlo, e incluso leerlo, son episodios externos de una actividad que encierra en sí misma varias significaciones. Se podría realizar una radiografía sobre este tipo de actividades para desentrañar los rasgos de su verdadera naturaleza ${ }^{1}$. Una biblioteca refleja, en buena manera, el espíritu y las preferencias culturales de la persona que se dedica a estos menesteres. Podríamos preguntarnos sucesivamente si es una necesidad intelectual la que empuja a su propietario, una curiosidad de bibliófilo, puro coleccionismo o un impulso mercantil. Cada uno de los rasgos citados generará distintos conceptos y usos de estas entidades culturales. Pero lo que es evidente es que cada uno en su conjunto, nos revela los perfiles de la cultura dominante que impera en una sociedad y en un tiempo concreto, así como las corrientes ideológicas más representativas. Luis Miguel Enciso, en una publicación a la que aludiremos de forma reiterada en este artículo escribe sobre estos asuntos:

En los últimos años, a la dificultad de conceptualización inicial y a la complicada tarea de encontrar satisfactorios cauces metodológicos y pedagógicos, se ha añadido un esfuerzo sobreañadido: el de diferenciar la cultura de élite y la cultura popular, la cultura escrita y la cultura oral. Por si fuera poco, hoy se abre camino en la investigación una tendencia que no acaba de encontrar identidad propia: la Historia de las mentalidades (2002: 35 ).

6 Pero los hechos culturales no son monolíticos sino diversos, circunstancia que nos permite delimitar las diferentes adscripciones sociales de las bibliotecas. Son clásicas las entidades de este género que nacieron y se desarrollaron en establecimientos religiosos como conventos, monasterios, iglesias y otros, que se convirtieron en verdaderos centros insustituibles para la conservación y divulgación del pensamiento de todas las épocas. Poco a poco, el nacimiento de las Universidades - aunque muchas de ellas fueran deudoras del empuje eclesial-, ampliaron cualitativamente este panorama al incluir entre sus fondos obras alejadas de las preocupaciones teológicas o dogmáticas, pero manteniendo sus niveles de dependencia, unas veces eclesial y otras, civil o estatal.

El siglo XVIII modifica sustancialmente esta tendencia, aunque ya en décadas anteriores se había observado el cambio con ejemplos sobresalientes. Nos referimos a que en esta centuria en muchos países y desde luego en España, son ya gentes privadas las que fundan 
las bibliotecas a sus expensas que compiten, en algunos casos, con la excelencia de las públicas.

8 Pero desde una perspectiva sociológica esta presencia privada en el campo bibliotecario, tiene una vinculación social específica porque pertenece casi en su totalidad a las élites, a la nobleza o la burguesía adinerada que suele buscar en estas prácticas una forma asequible de ascenso, algún tipo de reconocimiento o de prestigio profesional. Este signo de distinción viene a significar en la práctica, una especie de «mercado alternativo» de alto rango que si bien servía para asegurar las necesidades de las capas sociales elevadas, tenía también sus efectos en otros terrenos. Entre ellos, la ampliación de los fondos temáticos de los libros que ya no estarían mayoritariamente ceñidos a las cuestiones religiosas, sino a los temas científicos en sentido amplio o a los jurídicos, los políticos, los médicos, los matemáticos y los humanísticos, por solo citar alguno de los campos más usuales.

9 Un rasgo más podríamos añadir a este breve esbozo de interpretación sociológica de las bibliotecas, y es el hecho de que la titularidad de estas entidades pertenecía generalmente a los varones, mientras que la presencia femenina en estos campos era ciertamente escasa.

Por otra vía, las bibliotecas privadas, que naturalmente estaban concebidas para el consumo interno y a veces casi exclusivo de sus poseedores, tuvieron mucho que ver con otros acontecimientos de las historias nacionales. En España, las normas impuestas por la censura solía tener un frente triple casi siempre vinculado a las cuestiones religiosas, políticas o científicas cuyos libros estaban prohibidos en el caso de que fueran ediciones nacionales, y fuertemente perseguidos los que transitaban a través de las importaciones comerciales habituales bien por vía terrestre o marítima. A pesar del férreo control ejercido por el Santo Oficio, en determinadas épocas, muchos libros burlaban los trámites fronterizos de modo fraudulento ${ }^{2}$. A veces los clérigos los ocultaban debajo de sus amplios ropajes, los comerciantes lo hacían en sus carros o vehículos donde transportaban las mercancías, mientras que los viajeros comunes cruzaban las fronteras empleando cualquier tipo de camuflaje idóneo para conseguir sus propósitos. En definitiva, de lo que se trataba era de vulnerar los mecanismos legales establecidos y así poder conectar con la producción editorial de otros movimientos europeos. Precisamente, una de las novelas de muy reciente aparición en el mercado español escrita por el conocido miembro de la Real Academia Española de la Lengua, Arturo Pérez Reverte, aborda esta temática de una manera muy expresiva. En la contraportada del libro se comentan dos ideas básicas que le sirvieron para desarrollar el entramado argumental de la obra:

A finales del siglo xVIII, cuando dos miembros de la Real Academia Española, el bibliotecario don Hermógenes Molina y el almirante Pedro Zárate, recibieron de sus compañeros el encargo de viajar a París para conseguir de forma clandestina los 28 volúmenes de la Encyclopédie de D'Alambert y Diderot, que estaba prohibida en España, nadie podía sospechar que los dos académicos iban a enfrentarse a una peligrosa sucesión de intrigas (2015: contraportada).

Y unas líneas más adelante de la misma contraportada, el autor ratifica con su palabra otras ideas también avanzadas por nosotros en párrafos anteriores:

Hombres buenos narra la heroica aventura de quienes, orientados por las luces de la razón, quisieron cambiar el mundo con libros cuando el futuro arrinconaba las viejas ideas y el ansia de libertad hacía tambalear tronos y mundos establecidos (2015: contraportada). 
11 Hay todavía otros aspectos interesantes que ayudan a comprender el significado final de las bibliotecas y el perfil de sus fundadores, sobre todo cuando las consideramos como un camino efectivo para conocer la historia de las mentalidades. Parecería que el fomento de la lectura es una de las finalidades básicas de las bibliotecas, cuando no su finalidad única, sin embargo, se advierten conductas muy dispares en el comportamiento de los lectores. Unos leen ávidamente todo cuanto pueden mientras que otros, sin renunciar a la lectura, gozan fundamentalmente con la posesión del libro. Este hecho nos hizo recordar alguna de las interesantes reflexiones divulgadas por Pierre Bayard sobre esta cuestión. Habría que desacralizar el ejercicio de la lectura porque, «nous vivons encore dans une société en voie de disparition» (2007: 14). A la vista de estos postulados y quizás, como resumen, pone en tela de juicio si es necesario leer un libro para poder hablar con propiedad acerca de su contenido. Toda una nueva y sugerente teoría de la lectura aflora de sus palabras que adquieren su mayor significado cuando afirma más adelante, «car parler de livres non lus est une véritable activité de création, aussi digne, même si elle est plus discrète, que des activités plus reconnues socialement»(2007:160). El análisis de este poder creador revelará la personalidad tanto del lector como del no lector, sumergiendo el proceso de leer en un entramado mental complejo y plural.

12 Aunque pudiera parecer, dadas las circunstancias académicas y culturales de la España de la época, que el número de bibliotecas privadas debería ser pequeño, la verdad es que no era asín ${ }^{3}$ Aún reconociendo que la privacidad de estas iniciativas dificultaba a veces su cuantificación e incluso su localización, dado que muchas veces sus dueños las trasladaban a sus lugares preferidos, existe documentación abundante para seguir el rastreo al menos de las principales. El profesor Enciso Recio en su obra ya citada, recoge con suficiente amplitud diecinueve bibliotecas repartidas por todo el territorio español en el siglo XVIII, aparte de otro nutrido grupo de bibliotecas de nobles, profesionales y otros grupos sociales que existieron en Madrid en esta centuria y que rebasan nuestro campo de estudio en el presente trabajo. De ellas, siete pertenecen a la primera mitad del siglo, cuyos propietarios eran los siguientes: Teodoro Ardemans, Felipe de Castro, el padre Flórez, el padre Isla, el marqués de Dos Aguas, el padre Sarmiento y el padre Feijóo. De los citados, cuatro son religiosos mientras que el resto tienen profesiones diversas aunque siempre destacadas. Las doce correspondientes a la segunda mitad del siglo pertenecieron a los siguientes propietarios: la biblioteca de Cámara de Carlos III, el conde de Águila, Pedro Rodríguez de Campomanes (Soubeyroux, 1982), Gaspar Melchor de Jovellanos, Sebastián Martínez, Meléndez Valdés, Pablo Antonio de Olavide, Pedro José Pérez Valiente, Vicente Pulciani, Francisco Xavier Represa y Salas, y, finalmente, la de Juan Sempere y Guarinos ${ }^{4}$, a las que habría de sumarse las pertenecientes a otros profesionales residentes en Madrid. Se da la circunstancia de que entre todos ellos, ninguno perteneció a la vida religiosa.

13 Cabría preguntarnos, llegado este punto, sobre los sistemas de aprovisionamiento que ponían en práctica los propietarios de las bibliotecas privadas, o, lo que es lo mismo, de dónde nutrían sus fondos. Naturalmente que una buena parte procedía de las gestiones personales en el entorno de la compra-venta de libros, generalmente propicio a todo tipo de transacciones, también de las herencias recibidas, de las testamentarías que daban lugar a los inventarios denominados post mortem. Todo ello si la herencia aceptada no se dividía o enajenaba como también solía ocurrir en ocasiones ${ }^{5}$. Hechos de naturaleza política pero con un efecto inmediato entre las comunidades religiosas -como la expulsión de los jesuitas o las desamortizaciones llevadas a cabo en el siglo XIX- tuvieron 
un impacto considerable sobre el flujo de libros de unas manos a otras o de unas instituciones a otras. Muchos fondos de los conventos suprimidos fueron a parar a las bibliotecas públicas provinciales aprobadas en noviembre de 1813 o a los institutos de enseñanza media que poco a poco fueron implantándose, o a determinadas Universidades que los reclamaban (Martínez, 1992). Pero también hubo un mercadeo privado protagonizado por avispados bibliófilos, o eruditos con recursos, que aprovechaban las ocasiones obteniendo buenos resultados para sus colecciones personales.

14 Uno de los personajes más interesantes en el mundo de la biblioteconomía española fue Bartolomé Gallardo y Blanco, un hombre de entre siglos ${ }^{6}$ que tuvo una vida especialmente agitada en los ámbitos políticos y literarios. Nombrado Bibliotecario de las Cortes, en Cádiz ${ }^{7}$ miembro activo de la lucha antinapoleónica, renombrado anticlerical, sufrió numerosos reveses en su vida pública: cárcel, destierro, exilio, procesos y toda suerte de polémicas periodísticas. Pero en medio de tantas vicisitudes, siempre mantuvo una extraordinaria pasión por los libros lo que le permitió crear un patrimonio bibliográfico considerable - no siempre bien visto por determinados círculos- a través de sus viajes y relaciones. Una de las polémicas más ácidas precisamente sobre esta presunta avidez de Gallardo sobre los libros ajenos, fue protagonizada con Serafín Estébanez Calderón (conocido con el seudónimo de «El Solitario»), un escritor, poeta y costumbrista, nacido en Málaga en 1799. Estébanez le dedicó el famoso soneto titulado "A don Bartolo Gallardete», donde censuró sin cortapisas estos hechos ${ }^{8}$. En 1836, Bartolomé Gallardo compró una finca en los alrededores de Toledo llamada «La Alberquilla» adonde trasladó su gran biblioteca que en ese momento estaba dispersa por diversos lugares de España. Durante el resto de su vida dedicó gran parte del tiempo a sus tareas investigadoras y de erudición llevadas a cabo en la finca citada, que también se convirtió en centro de reunión con hombres de letras bien conocidos.

Documento 1. - Edificio La Alberquilla, Toledo.

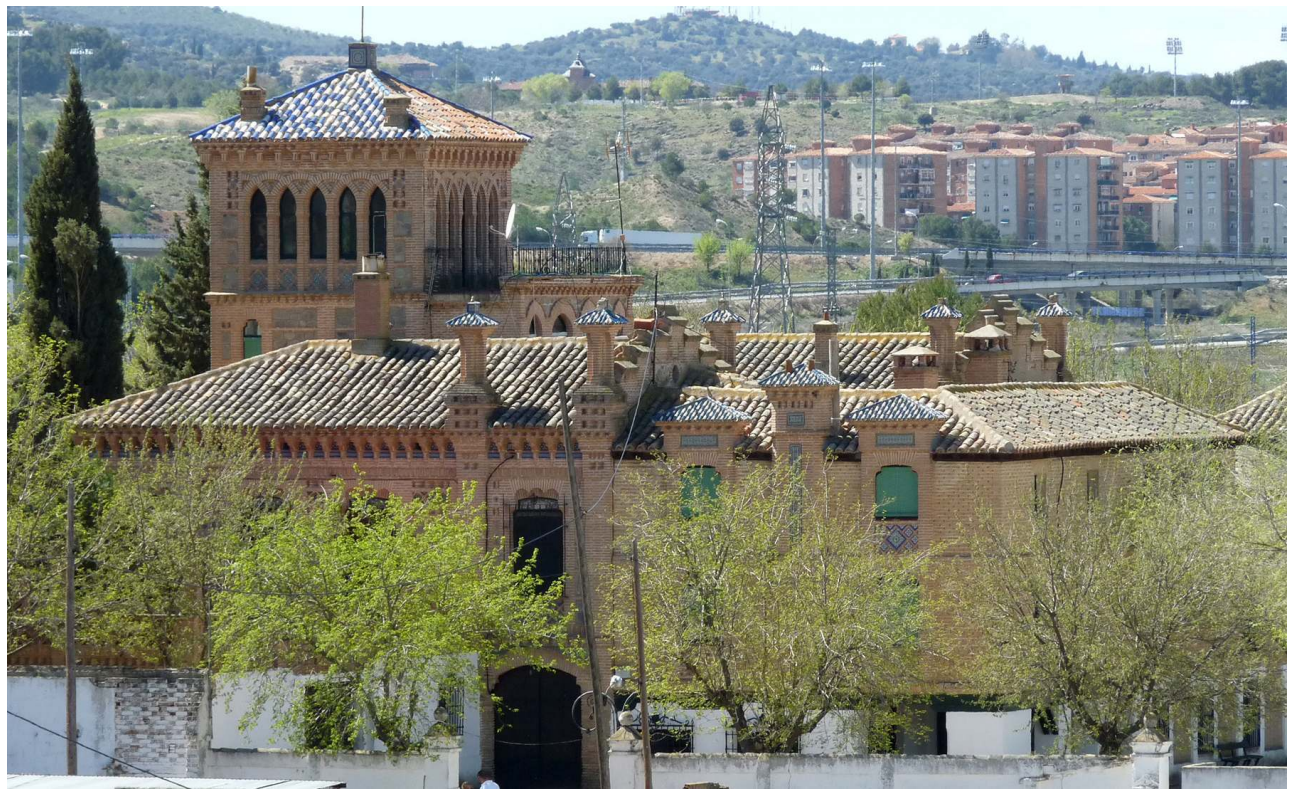

Foto de Valérie Molero, 2015.

15 Las donaciones privadas pueden también considerarse como generosas contribuciones que ayudaron a la configuración de estos centros culturales. Sin embargo, unos centros de 
provisión fijos y cada vez más extendidos, fueron las librerías. Solían editar sus propios catálogos que andando el tiempo se convirtieron en piezas inevitables de consulta para los bibliófilos. A veces, alguna de estas librerías, o también personas particulares, utilizaban otros medios para divulgar sus ofertas. En el Diario de Madrid del 15 de marzo de 1842 se publica la «relación que se halla de venta en el despacho de la señora viuda de Jordán e Hijos». En la misma nota se indica que «en la librería de la calle de Atocha número 47 , hay un surtido de semanas santas, devocionarios y ejercicios cotidianos a precios arreglados». Otras formas de promoción de libros, fondos o novedades editoriales, solían organizarse en las llamadas reboticas que no eran sino tertulias literarias en las trastiendas de estos negocios con fines de difusión cultural aunque, a veces, las discusiones pudieran transcurrir por otros derroteros, entre ellos los políticos.

Por eso era habitual la lectura de la prensa clandestina o algún texto o folleto vetado por la censura (Urreiztieta, 1985). En definitiva, se aprovechaba cualquier medio para facilitar la lectura de estos productos culturales a determinados sectores sociales que no podían consultarlos por su cuenta.

17 Después de estas reflexiones sobre los aspectos genéricos, tanto internos como externos de lo que llamamos bibliotecas privadas y toda su problemática, analizaremos dos realidades concretas en tiempos históricos alejados uno del otro, pertenecientes a propietarios distintos y profesiones bien diferenciadas donde se pueden observar multitud de referencias y comparaciones. Estudiaremos primero el caso del Greco antes de analizar la biblioteca de Francisco Cerdá y Rico.

\section{La biblioteca privada de Dominico Theotocópuli, «el Greco»}

El 7 de abril de 1614 murió en Toledo el célebre pintor cretense Dominico Theotocópuli, más conocido como el Greco. En esa ciudad vivió los últimos cuarenta años de su vida y en ella ejecutó la parte más significativa de su extensa obra. Con motivo del cuarto centenario de su muerte, la capital toledana organizó a lo largo del año 2014 una serie de exposiciones conmemorativas en unos lugares denominados «espacios Greco», donde se conserva todavía buena parte de sus trabajos, a los que se añadieron otros muchos procedentes del extranjero que fueron cedidos por sus propietarios para esta conmemoración ${ }^{9}$.

Después de su muerte, la figura de este pintor entró en una zona de sombras que no desapareció hasta bien entrado el sigloxix gracias a los trabajos de algunos investigadores; pero sería a partir de 1908, con la publicación de la obra titulada El Greco escrita por Manuel B. Cossío (1983), uno de los hombres más acreditados de la Institución Libre de Enseñanza ${ }^{10,}$ cuando el «renacimiento» de este pintor alcanzó rango universal.

El Museo Nacional del Prado, de Madrid, quiso sumarse a este tipo de eventos organizando una exposición en colaboración con la Biblioteca Nacional cuyo título fue: $\mathrm{La}$ Biblioteca del Greco. Con ella se pretendía visualizar la trayectoria intelectual de un hombre que había vivido experiencias personales muy diversas, desde Creta, su tierra natal, pasando por Venecia, Roma y, finalmente, Toledo. Acostumbrados los historiadores del arte a manejar libros que detallaban desde todos los ángulos las peculiaridades de su técnica pictórica, resulta extremadamente interesante esta iniciativa de las entidades organizadoras del cuarto centenario por adentrarse en las interioridades formativas de 
un hombre, excepcionalmente celoso de su intimidad. Porque, realmente, lo que presentían los expertos y la Exposición lo demuestra, es el grado de impacto que determinados libros y las lecturas consiguientes -en suma, su biblioteca-, tuvieron en los espacios creadores del cretense, tanto desde el punto de vista técnico como el doctrinal o religioso.

De la interesante obra de Cossío citada, se pueden obtener numerosas conclusiones. Una de ellas nos hace recordar -salvadas las distancias- las palabras de Pierre Bayard ya recogidas líneas arriba, cuando planteaba la posible paradoja que supone poder hablar de los libros no leídos. Por su parte, Cossío, plantea con sutileza una nueva dicotomía cuando afirmaba:

Sin embargo, muchos son los que pasan por ella [se refiere a Toledo] sin haber visto al Greco, y muchos más aún - puede decirse que la mayoría- los que han mirado y no lo han visto ; porque, para ver, hay que saber hacerlo (1983: 21).

Él mismo parece iniciarnos en este nuevo camino cuando dice que, «la biblioteca del Greco es la primera y más sintética confirmación que dan los hechos, de la personalidad y carácter del artista» (1983: 63).

Correspondió al hijo del pintor, Jorge Manuel, realizar el primer inventario de los bienes de su padre poco después de su muerte. A través de este trabajo se pudo conocer que eran 130 los libros de su biblioteca, que posteriormente fueron corregidos al alza en un segundo listado. De todos ellos, fueron 39 los seleccionados para la exposición del cuarto centenario reproducidos en el catálogo oficial (Docampo y Riello, 2014).

Quisieron los organizadores adentrarse en el conjunto de ideas subyacentes en toda su obra y también limpiar de tópicos creados en torno a su figura ${ }^{11}$, en definitiva, recrear su perfil intelectual recurriendo a fuentes indirectas pero fidedignas, como los libros y documentos que el artista consultó a lo largo de su vida.

Coinciden los intérpretes de su obra en afirmar que el Greco era una persona bien formada en el ámbito cultural, incluso es calificado de erudito y humanista por la extensión de sus conocimientos, aunque no llegara a manejar aceptablemente la lengua del país que le dio acogida. Pero lo que es indudable, a la luz de la variada temática de los libros que fue almacenando en su biblioteca privada, es que la lectura de tantos trabajos editados por hombres eminentes, repercutió en su obra artística en todos los aspectos. Y ello a pesar de que los inventarios post mortem realizados por su hijo estaban probablemente incompletos, ya que hay sobradas pruebas de la dispersión de algunas de sus obras que él conoció pero que no figuran en los listados.

Como otros hombres ilustres de la época, el Greco fue un lector peculiar, porque escribía mientras leía anotando sus reflexiones en los espacios marginales de los libros que, según sus biógrafos, se acercaron a 20.000 palabras. Tal ocurrió, entre otros, con las Vidas de Giorgio Vasari, un clásico para conocer las biografías de escultores, pintores y arquitectos de su tiempo, y con Los diez libros de arquitectura, de Marco Vitruvio, considerado como el canon de la arquitectura antigua. Además, a esta curiosa forma de lectura que podría calificarse de interpretativa y crítica, hay que sumar los más de 500 documentos sobre su vida que pudieran ser considerados como una ampliación de las notas marginales incluidas en los libros citados. Todas estas versiones manuscritas nos ayudan a conocer también el marco de sus relaciones personales que posteriormente reflejaría en varios cuadros, entre ellos el de Covarrubias y el de un médico, cuya amistad podría estar vinculada a la posesión o manejo de algún libro por parte del cretense. 

ya ha quedado dicho. José Riello presenta una primera valoración concreta y acertada de los dos inventarios que realizara el hijo del pintor, Jorge Manuel, en 1614 y 1621 respectivamente. Dice así sobre este asunto:

Lo que a primera vista destaca en los dos es la variedad lingüística y temática de su biblioteca, ya que el Greco tenía libros en griego, italiano y «de Romanze» y, además de algunos relacionados con las artes, sobre todo de arquitectura, clásicos como Homero, Aristóteles, Flavio Josefo, Jenofonte, Luciano, Plutarco o Esopo, y modernos como Petrarca o Ariosto, junto con textos de santos como Justino, Dionisio, Juan Crisóstomo o Basilio, hagiografías y los decretos del Concilio de Trento, libros que consideraría esenciales para afrontar la representación de los asuntos religiosos con decoro y ateniéndose a la doctrina (2014: 43).

Aparte de estas indicaciones sumarias, fue evidente a la vista de los inventarios, la importancia que el Greco otorgó a la arquitectura como ciencia que pretendía englobar al resto de las artes, especialmente la escultura y la pintura. El conocimiento de las leyes de lo arquitectónico, tan extendido en su tiempo y en el precedente, encuentra en este pintor, ya toledano de adopción, un refugio inevitable para dotar a su obra de una categoría singular. También elogia la escultura y sus procedimientos expresivos; sin embargo todo este tipo de creencias o de opiniones, no le llevan a silenciar sus preferencias acerca de la pintura. Los pronunciamientos sobre este asunto son categóricos. Así, en la introducción a la sección titulada «La pintura como ciencia especulativa», donde se reproducen y comentan algunas de las obras expuestas, se escribe lo siguiente: "Y además es la única [se refiere a la pintura] entre las artes capaz de representar "cosas imposibles" como las que constituyen el acervo visual de la imaginería religiosa» (2014: 149). No hay duda, según se indica en la introducción citada, que estas conclusiones fueron el producto de las lecturas de tratados artísticos y libros sobre perspectiva y aritmética que también formaban parte de su colección particular.

El tema religioso es un asunto capital para comprender en toda su complejidad la producción pictórica del Greco ya que sus destinatarios fueron casi siempre entidades religiosas o civiles, pero impregnadas por un fuerte sentimiento derivado de la religiosidad oficial. En su biblioteca aparecen obras debidas a los Padres de la Iglesia y otras fuentes similares que le permitieron conocer los textos de la Biblia y las bases de la teología católica. También utilizó los decretos del Concilio de Trento, como fuentes absolutamente prioritarias para la visualización e interpretación de los hechos sagrados.

El problema de la adecuación de sus propias convicciones religiosas privadas con la ortodoxia de los poderes fácticos de la época que estaban entregados a la causa de la contrarreforma, fue progresivamente resuelto con el paso del tiempo. Su desafortunada experiencia -que motivó su alejamiento de la corte- se inició nada más llegar a España cuando Felipe II le encargó un cuadro sobre El martirio de San Mauricio para el Monasterio de El Escorial, que no sintonizó con los deseos del monarca por la inadecuación iconográfica entre la noción del martirio y la versión pictórica elegida por el cretense. Quizás este hecho provocó su traslado a Toledo y el inicio de una carrera ascendente que ya no se detendría hasta su muerte. El Greco llegó a Toledo probablemente en el año 1577, pero lamentablemente para sus intereses profesionales, Felipe II había trasladado su Corte desde la capital toledana a Madrid en 1561. Todo el marco clientelar que se abría ante su horizonte artístico estaba representado mayoritariamente por entidades religiosas, como conventos, la catedral y otros grupos afines. De ahí que los modelos de expresión tuvieran que buscar un punto de encuentro entre lo figurativo y lo teológico, 
que exigió al pintor una lectura más a fondo de sus propias fuentes para evitar el rechazo conceptual de las autoridades y de los mecenas que, a fin de cuentas, habían de encargarle sus trabajos.

En el cuadro Las lágrimas de San Pedro que se exhibe en la colección del Hospital Tavera, de Toledo, se acompaña el lienzo con un pie explicativo que refleja perfectamente la adecuación con la teología tridentina del pintor cretense a través de las obras recreadas con sus pinceles: «El Greco expresó intensamente dos de los aspectos fundamentales de la reforma tridentina, el arrepentimiento y la penitencia, y su consecuencia, la salvación», principios que tanta fortuna tuvieron en la España barroca.

31 A pesar de que los inventarios de sus obras no incluyen las fechas de adquisición, todo parece indicar que sus visiones más personales estuvieron relacionadas con algunos libros que pertenecieron al «núcleo duro» de su biblioteca. Es lo que se esperaba de un hombre que terminó siendo afectado por las contingencias del tiempo histórico en que vivió.

\section{Francisco Cerdá y Rico, un bibliotecario Ilustrado}

Nuestro acercamiento hacia este prestigioso ilustrado fue completamente casual al ser el fruto de una investigación sobre un tema sin conexión con las bibliotecas. Por lo tanto, no fue un personaje buscado, sino un hombre encontrado entre la tormenta de datos que proporciona el manejo asiduo de los archivos. Podríamos decir que fue un efecto colateral sobre el cual planeamos posteriormente numerosas iniciativas, alguna de las cuales están en trance de realización.

Hace dos años, aproximadamente, nos propusimos realizar un trabajo de investigación amplio sobre los conflictos matrimoniales en Madrid, durante la segunda mitad del siglo xVIII. Naturalmente, comenzamos a frecuentar los archivos más importantes de la capital de España, especialmente el Archivo Diocesano perteneciente a la Iglesia, y que por la naturaleza del objeto investigado, nos parecía que era prioritario. El manejo de fuentes originales representado por los legajos manuscritos que describían con toda minuciosidad los pasos de cada proceso, se convirtió en una fuente inagotable de informaciones de todo tipo que nos conducían por derroteros no previstos.

En una de las centenares de demandas de esponsales que analizamos, nos encontramos con una presentada el 1 de junio de 1777 por una tal Antonia Moreno, vecina del pueblo madrileño de Navalcarnero. Era soltera, tenía 25 años y según confesaba en el escrito principal de la demanda, «la habían quitado el honor» sin que la otra parte cumpliera la palabra de casamiento otorgada en su momento. Conforme nos adentrábamos en la lectura del expediente, descubríamos más datos, entre ellos, que la supuesta persona incumplidora se llamaba Francisco Cerdá y Rico, un hombre culto y relevante, muy próximo a las esferas oficiales. Antonia Moreno era su sirvienta y de esta relación nacieron dos hijas que llevaron el apellido de su padre biológico por mutuo consenso, siendo bautizada la primera de ellas con el nombre de Francisca. Incluimos estos datos por la incidencia que, andando el tiempo, la tal Francisca iba a tener en el reparto de la herencia de su padre y, de paso, en el destino final de los libros de su biblioteca.

Toda la demanda de esponsales presentada por Antonia Moreno - demanda que incluso se continuó ante el Tribunal de la Rota- está cuajada de hechos que describen la crueldad del demandado, lo que demuestra, según nuestro criterio, la doble moral que este hombre aplicaba a su vida: virtuosa en sus actos públicos, pero cicatera en este punto de su vida 
privada. No es el momento de adentrarnos en esta temática que probablemente será abordada por nosotros en otro lugar. Pero sí procede destacar que en algunos momentos se entrecruzan los hechos del pleito con nuestro objeto de estudio. Tal ocurre con la descripción que se hace de las diligencias fechadas el 3 de agosto de 1781 por las que Francisco Cerdá debía pagar inmediatamente a Antonia Moreno la cantidad de 100 ducados bajo pena de embargo, que era el importe parcial de una condena acordada por el Tribunal de la Rota. El día citado, se presentó el alguacil del Real Juzgado en la casa de Cerdá para reclamarle el pago de la deuda. Ante la negativa de éste, se le instó a que mostrase bienes equivalentes a la referida cantidad para hacer el embargo a lo que manifestó que solo tenía la biblioteca, pero que ésta era inembargable por ser de su uso. Finalmente, el demandado acordó abonar la citada cantidad para resolver la situación.

Francisco Cerdá ocupó diversos cargos públicos a lo largo de su vida profesional, todos ellos relacionados con el mundo de la cultura. Bibliotecario de la Real Biblioteca, Abogado del Colegio de la capital, Académico de la Real Academia de la Historia, secretario del Consejo y Cámara de Indias, condecorado con la cruz de Carlos III, estos son algunos de los puntos relevantes de su biografía. Como era de suponer, todos estos cargos le familiarizaron con las grandes colecciones de libros, con las compras y ventas de ejemplares raros y con el mercadeo inevitable con los profesionales de estas mercancías. Su cualificación profesional le llevó también a impulsar la reedición lujosa de obras escogidas que posteriormente engalanaron las bibliotecas y centros con los que estaba vinculado. Naturalmente, también creció en calidad y cantidad su propia biblioteca privada hasta convertirla en una de las más relevantes de la época.

Para el rastreo de este personaje y de su biblioteca, hemos seguido diversas fuentes. La primera de ellas fue la obra escrita por Ángel González Palencia titulada: Eruditos y Libreros del Siglo XVIII, donde aparte de otros escritores destacados de esa centuria, se incluía un largo apartado dedicado a Cerdá y Rico (1999: 3-167). En 1999, un grupo madrileño de libreros acordó reeditar esta última obra para conmemorar el cincuenta aniversario de la muerte del autor. Indispensable también fue la consulta de la obra escrita por Juan Sempere y Guarinos sobre los escritores de la Ilustración ${ }^{12}$. A su vez, y para completar el perfil de su figura y de su obra, consultamos los fondos madrileños del Archivo Histórico Nacional y también los del Archivo de Protocolos, especialmente para estudiar su testamento. Sempere y Guarinos, escribe que Cerdá,

[...] habiendo sido recibido por oficial de la Biblioteca Real, viendo las muchas preciosidades de que aquella consta, particularmente de buenos Autores Españoles antiguos, se dolió mucho de que estos estuvieran sepultados en el olvido (1969: 174).

Este fue el origen de sus iniciativas en torno al libro desarrolladas desde los puestos de la Administración en los que fue responsable. Además, solía complementar las ediciones con aportaciones personales en forma de prólogos, notas sueltas o noticias que pudieran afectar tanto a los autores como a las obras que proyectaba. Eran libros editados con esmero y destinados bien a instituciones de prestigio o a colecciones privadas de bibliófilos acaudalados. Estas ediciones vieron la luz en las imprentas españolas más acreditadas de la época, siendo la de Antonio Sancha la que con más frecuencia aparece, aunque también se sirvió de las de Joaquín Ibarra y Andrés de Sotos, entre otros grupos editoriales.

Debido a sus puestos de trabajo y al mundo de relaciones socio-profesionales que tejió a su alrededor, siempre contó con personajes destacados que favorecieron sus proyectos $\mathrm{y}$, en muchos casos, actuaron como mecenas. Tal fue el caso del Conde de Campomanes, el 
Conde de Floridablanca, el Marqués de Monreal, e incluso el Príncipe de la Paz con el que debió tener un acceso razonable a juzgar por el apoyo que le prestó en alguna obra concreta de la que daremos cuenta más adelante. Aparte del apoyo político o económico, también disfrutó de un amplio grupo de personalidades literarias que le animaron y asesoraron en sus empresas, entre ellos, Gregorio Mayáns, Francisco Antonio Borrull, José de Matamoros, Juan de Santander y otros académicos de la Real Academia de la Historia.

Las publicaciones más importantes impulsadas o editadas por Cerdá superaron la veintena, aparte de diversos manuscritos y otros trabajos proyectados. Habida cuenta de su pasión por la bibliofilia, es de suponer que la mayoría de ellas engrosaran su biblioteca privada. Aunque no disponemos de fuentes fiables que así lo acrediten, sí existen testimonios indirectos sobre el valor de su colección y el importante número de ejemplares que se acreditaron con ocasión de su testamento. La temática de estas obras era muy variada, oscilando entre obras en Latín, Literatura Española, Historia de España, Política y Derecho y Equitación.

Habiendo fallecido Cerdá el 5 de enero de 1800, en Madrid, muy pronto se dio a conocer el testamento.

Documento 2. - «Testamento otorgado por Francisco Cerdá y Rico, caballero de la Orden de Carlos III y miembro del Consejo Supremo de Indias, en 31 de diciembre de 1799», Archivo Histórico de Protocolos de Madrid (AHPM, tomo 21814, folios 172r a 176v).

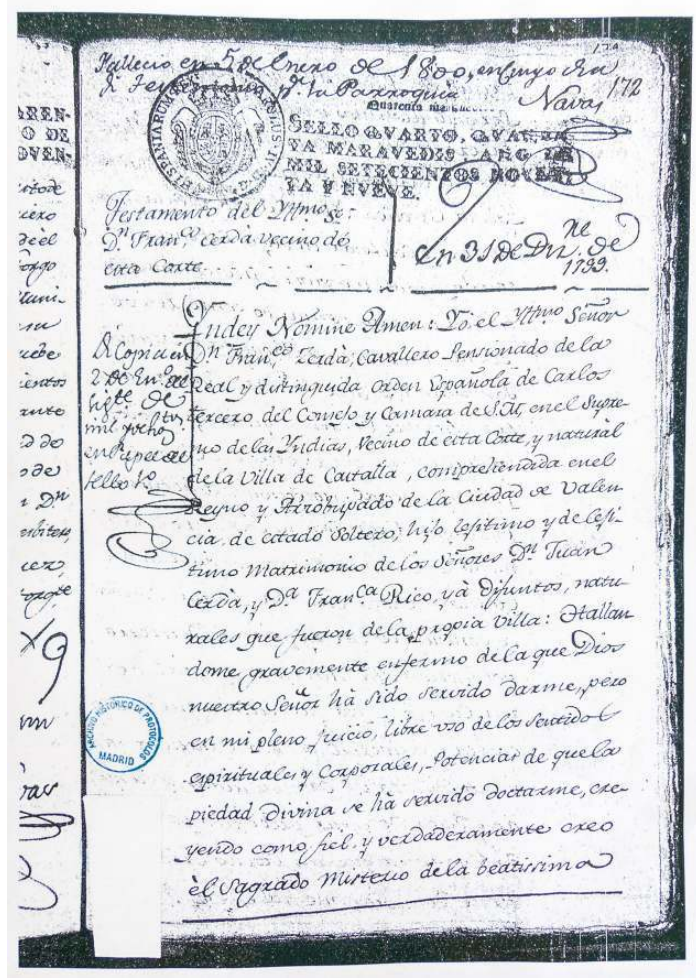




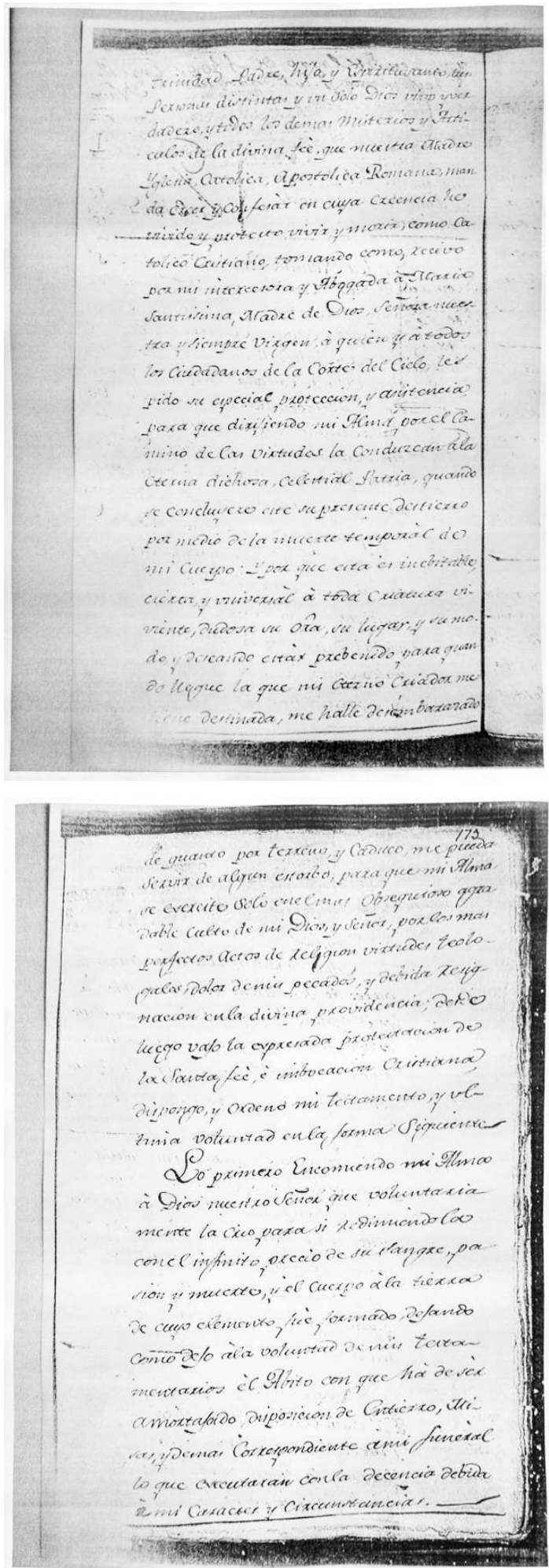




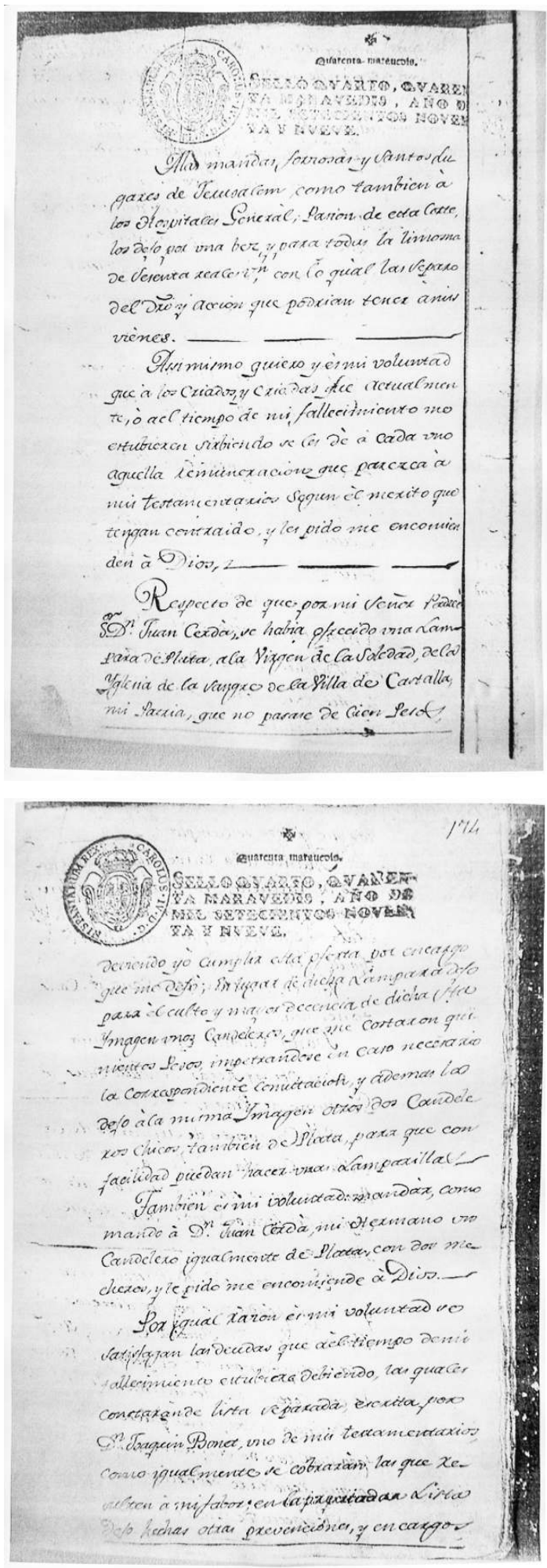



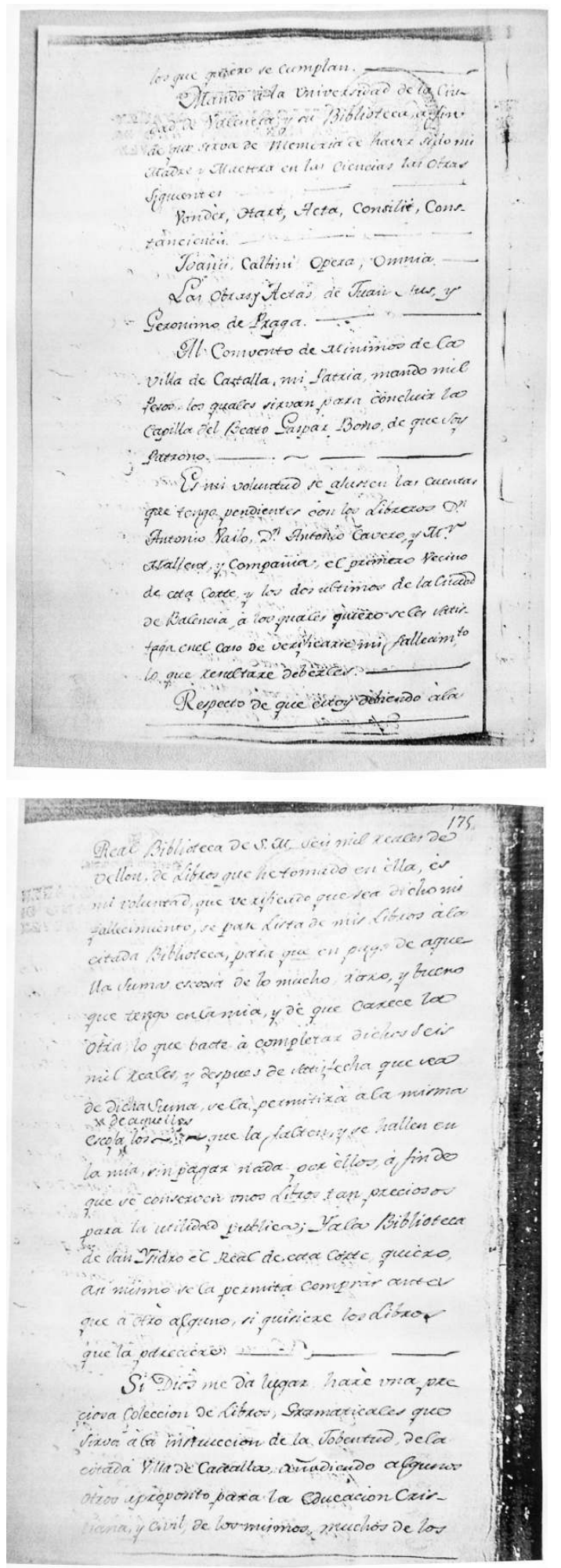

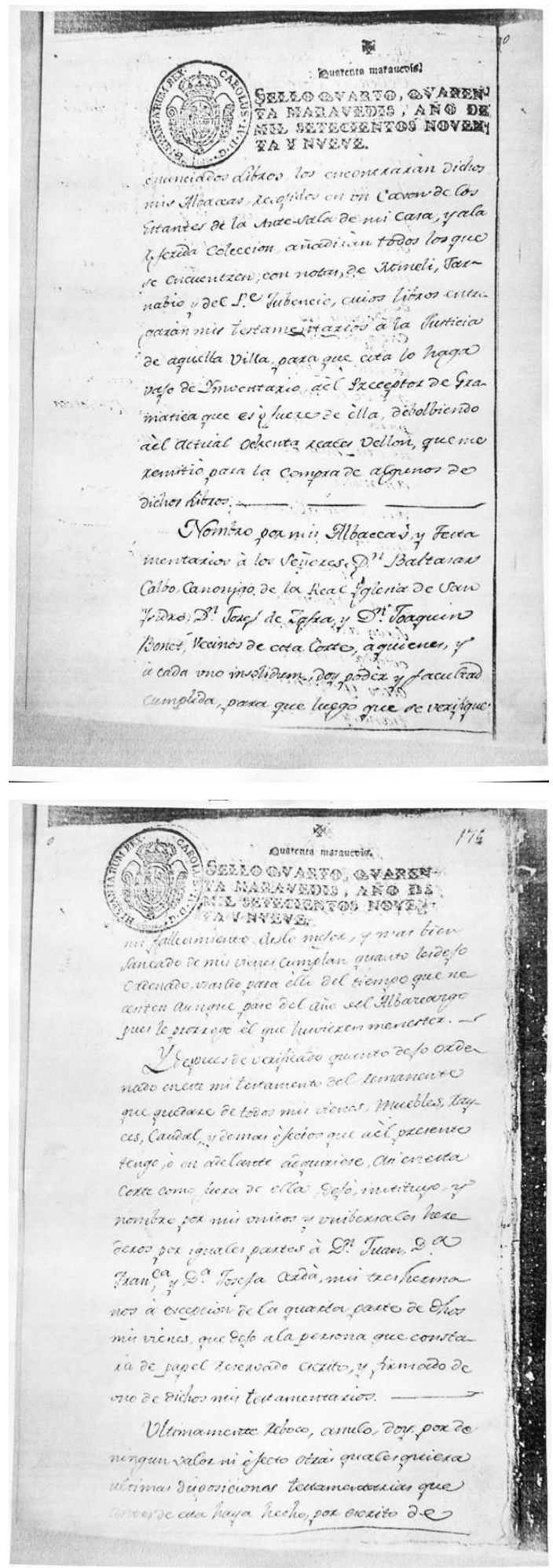


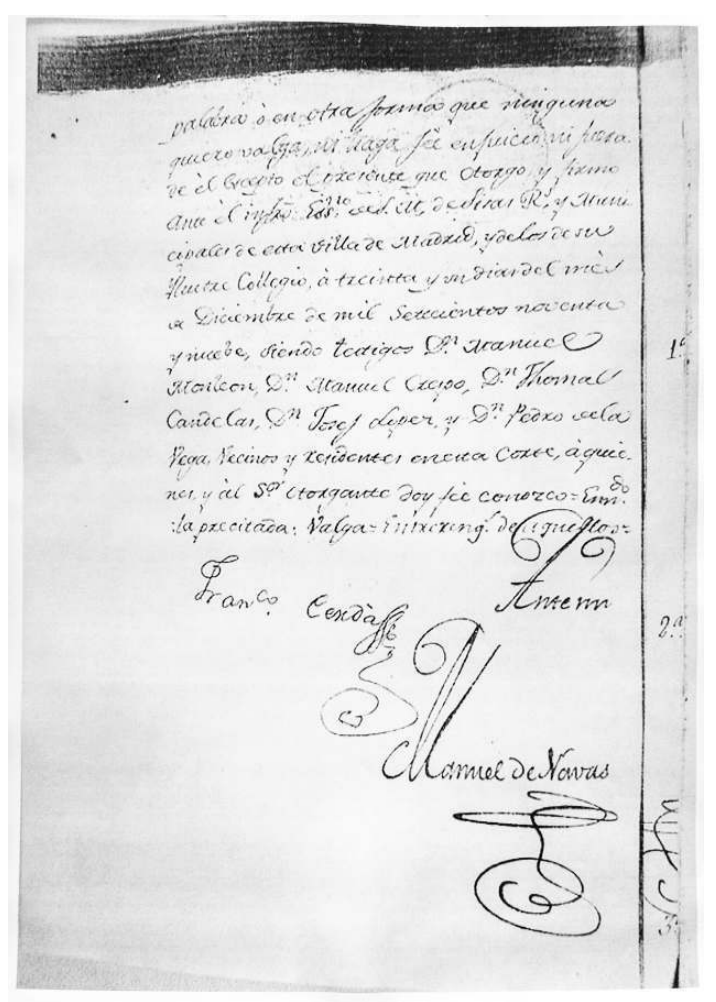

Aparte de las disposiciones testamentarias de carácter general o de otras con distinta finalidad pero que no afectan al objeto de nuestro trabajo, la verdad es que el testamento es una buena ocasión para adentrarnos en las peculiaridades de su biblioteca ya que nunca se había elaborado un catálogo con su contenido. Las últimas voluntades de nuestro hombre, son muy concisas y están redactadas con claridad.

Ordena que se entreguen a la Universidad de la Ciudad de Valencia y su Biblioteca las obras siguientes escritas por distintos autores: Acta Concilii Constancensis, Opera Omnia y Obras y Actas y de «que se ajusten las cuentas que tengo pendientes con los libreros Dn. Antonio Bailo, Dn. Antonio Cavero y Mr. Mallent y Compañía». El finado reconoce que en ese momento debe a la Real Biblioteca seis mil reales de vellón «de libros que he tomado de ella», y para subsanar esta deuda propone que la citada Biblioteca «escoja de lo mucho, raro y bueno que tengo en la mía y de que carece la otra, lo que baste para completar dichos seis mil reales». También autoriza a sus albaceas para que cedan a dicha entidad otras obras de su interés, sin pagar nada, «a fin de que se conserven unos libros tan preciosos para la utilidad pública». Indica, asimismo, que a la Biblioteca de San Isidro el Real de esta Corte se le permita comprar los libros que estimara oportuno antes que a ningún otro. Recuerda que «en un cajón de los estantes de la antesala de mi casa» guarda, entre otros, «una preciosa colección de libros gramaticales» que deben entregarse a la villa de Castalla ${ }^{13}$ para que sirvan de instrucción a la juventud, a los que deberían añadirse otros ejemplares relacionados con la educación cristiana y civil.

El testamento se había firmado el 31 de diciembre de 1799, ante el escribano de Madrid, Manuel de Navas, y en él se designaron como «únicos y universales herederos por partes iguales» a sus tres hermanos, excepción hecha de la cuarta parte de sus bienes que deberían ir a parar a la persona cuyo nombre se incluía en un papel reservado. Anexo al testamento figuraban dos Memorias con otros detalles concretos sobre la situación y 
destino de sus bienes de todo tipo, aunque nosotros solo nos ceñiremos a aquellos aspectos relacionados con el mundo de los libros.

Documento 3. - «Memoria testamentaria de Francisco Cerdá y Rico, en 30 de diciembre de 1799» (AHPM, tomo 21814 , folios $177 \mathrm{r}$ a $178 \mathrm{v}$ ).
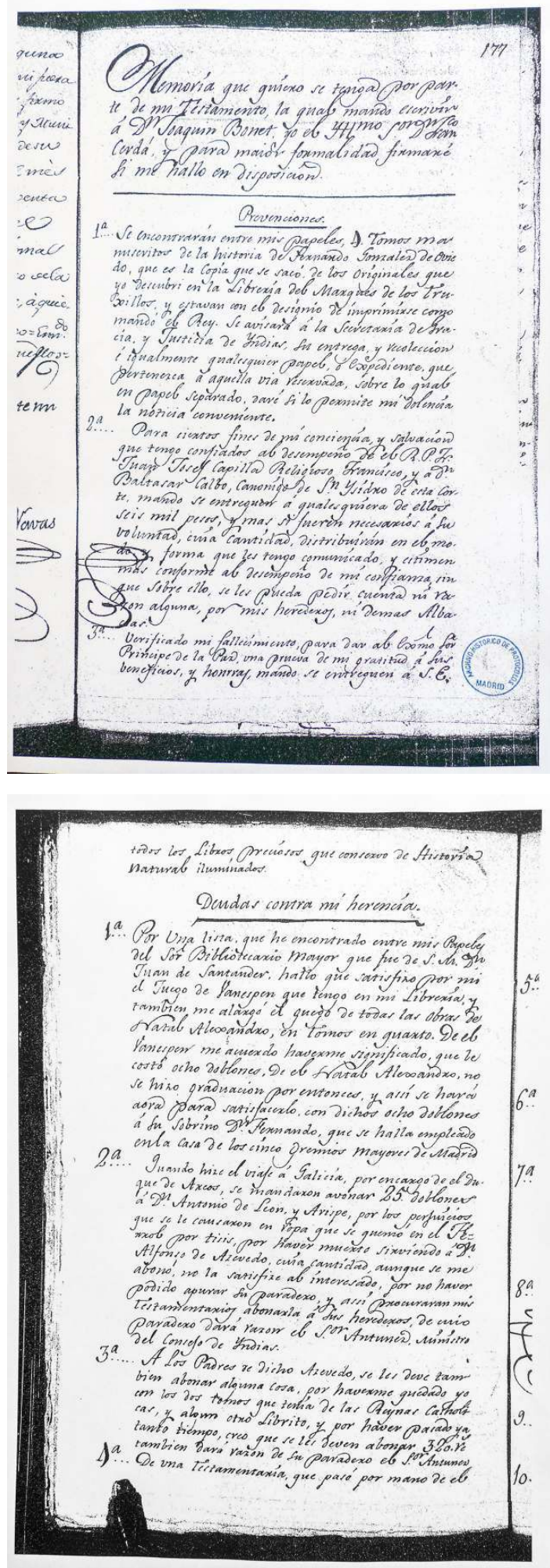

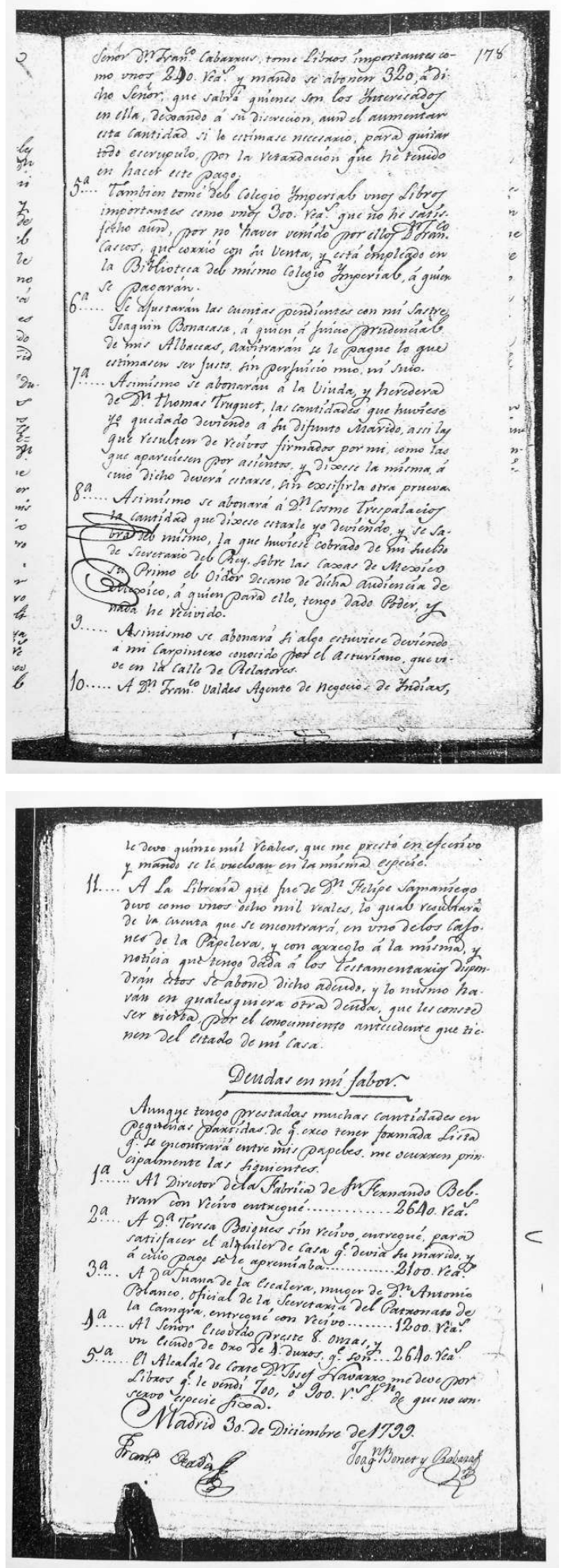

En la primera de las Memorias, Cerdá quiso dejar público reconocimiento de gratitud al Príncipe de la Paz, para lo cual mandó que se le entregaran «todos los libros preciosos que conservo de Historia natural iluminados». En el mismo lugar se deja constancia de las deudas contraídas y que no habían sido satisfechas, por lo que sus albaceas deberían satisfacer su voluntad de cumplimentarlas. Es ésta una buena ocasión para conocer parte de su mundo de relaciones y del ajetreo constante que tuvo en torno al mercado de los 
libros. En un viaje que hizo a Galicia dejó a deber los dos tomos de las Reinas Católicas y algún otro librito, para lo que deberán destinarse trescientos veinte reales. De la testamentaría de Francisco Cabarrús «también tomé libros importantes» por lo cual pide que se entreguen a dicho señor trescientos veinte reales. «También tomé del Colegio Imperial unos libros importantes como unos trescientos reales que no he satisfecho aún». La última de las deudas reconocidas se refiere a la librería que fue de Felipe Samaniego, a la cual «debo como unos ocho mil reales, lo cual resultará de la cuenta que se encontrará en uno de los cajones de la papelera».

Pero Cerdá también incluye en sus disposiciones testamentarias algunas deudas a su favor que se reflejan con todo detalle en esta Memoria. Una de ellas está relacionada con el Alcalde de Corte D. José Navarro, el cual, sin precisar la deuda exacta, «me debe por libros que le vendí, 700 ó 900 reales de vellón».

La Segunda Memoria de las anunciadas -firmada el 1 de enero de 1800- contenía el «papel reservado y firmado» con el nombre de la persona que iba a completar la lista de los herederos principales. Se trataba de doña Francisca Cerdá,

[...] mi hija natural, á la qual se dará la quarta parte de mí herencia, hechas las deducciones $\mathrm{q}^{\mathrm{e}}$ resultan de mi testamento, como assí lo tengo confiado á mís tres Albaceas y al Confesor el R.P. Fr. Juan Josef Capilla Religioso Francisco Observante en el conbento de esta Corte, y encargo á dicha mi hija, viva con el Santo temor de Dios, y la doy mí bendición. Madrid. $1^{\circ}$ de enero de 1800 (AHPM, tomo 21814, folio 179r).

La presencia de esta persona complicaría todo el proceso de la herencia, ya que desde el primer momento sus exigencias desbordaban las previsiones de los albaceas. De entrada anunció que iba a contraer nupcias próximamente (se casó el 6 de julio de 1800) y que necesitaba dinero, no menos de 6.000 reales de vellón, para sus necesidades. Ante la demora en la entrega del dinero solicitado, la heredera recurrió al Juez, quien pidió una respuesta a Joaquín Bonet que era el abogado del resto de los coherederos. Bonet escribió lo siguiente en relación a los bienes principales que dejó en herencia Francisco Cerdá: "Que el caudal que dejó dicho Señor (como V.S. sabe y es notorio), consiste todo en libros, que tardarán mucho en venderse». Añadía luego que el dinero obtenido hasta ese momento por la venta de otros enseres y propiedades, se habían invertido en el pago de deudas y obligaciones contraídas según las disposiciones testamentarias. Continúa escribiendo el letrado Bonet,

[...] todas estas consideraciones persuaden que no hay terminos haviles para dar á la $\mathrm{D}^{\mathrm{a}}$ Fran ${ }^{\mathrm{ca}}$ el dinero que pide, pues no hay herencia hasta no estar satisfechas las cargas (Archivo Histórico Nacional, Sección Consejos, Legajo 21369).

La pelea por la herencia iniciada por la hija del finado siguió por otros derroteros. Sus representantes legales plantearon ante el juez otras demandas, entre ellas, la redacción de un inventario detallado con todos los bienes, así como noticias documentadas sobre los bienes vendidos, los pagos efectuados y los remanentes que resultaran. Pero probablemente el detalle más significativo de las nuevas peticiones fuera el de pedir a los abogados de la otra parte la entrega de un juego de llaves que permitían acceder al cuarto de la testamentaría. Luego de un largo cruce de acusaciones recíprocas entre los abogados que representaban a las dos partes, el juez acabó por reconocer las razones del nuevo matrimonio, ordenando que se les entregara una de las llaves solicitadas. fondos de la biblioteca en el punto de mira de los albaceas. Unos dos años después de la 
muerte, el propietario de la casa que había ocupado Cerdá en vida, pidió a los herederos que la desocuparan y que pagaran el importe de los alquileres adeudados. Entre promesas no cumplidas y «apercibimientos de despojo», transcurrió prácticamente el año 1802 hasta que al final, el juez ordenó que en el plazo de ocho días los herederos cumplieran la ley. Sus abogados presentaron un escrito en el que prácticamente reflejaban con exactitud la situación de la biblioteca de Cerdá, o al menos lo que iba quedando de ella. Protestaron en su escrito por la «pretensión de que se despojen y pongan en la calle los efectos, consistentes casi todos en libros de un ministro, cuya buena memoria debía ser mirada con más consideración». Comunican al Juez las búsquedas infructuosas que están haciendo para encontrar un cuarto más reducido y así desalojar el antiguo, pero la cosa no es sencilla por la escasez de cuartos que es notoria en Madrid. Recuerdan que «se trata de la traslación de diez y ocho o veinte mil volúmenes, nada menos, que es preciso colocar, con sus estantes, en una casa proporcionada para su venta». Piden que se resuelva el caso de acuerdo con las normas que dicta la razón y la «epiqueiya ${ }^{14}$ » y solicitan al Juez «que se sirva desestimar el despojo solicitado por el administrador del cuarto mortuorio, ocupado por la librería y efectos de la testamentaría del difunto Ilmo. Señor Cerdá» (AHN, Sección Consejos, Legajo 21369).

51 Las fuentes consultadas por nosotros no nos indican la suerte final de esta serie incesante de pleitos e incidencias que rodearon la ejecución de las disposiciones testamentarias en nuestro campo de estudio de los bienes de Cerdá; pero sí ponen de relieve la dificultad de seguimiento que suele acompañar a muchas de las bibliotecas privadas laboriosamente conseguidas por personas relevantes. En la dispersión de muchos de sus fondos, cuando se producen, intervienen multitud de factores entre los que cabe destacar la actitud de las «nuevas manos» en las que quedan depositados su destino, esto es, la actitud de los herederos.

\section{A modo de epílogo}

52 Dos hombres ilustres, dos bibliotecas fundamentales en sus vidas profesionales y personales. En el caso del Greco, los libros de su biblioteca le permitieron ajustar sus convicciones religiosas que posteriormente contribuyeron a modificar sus escenarios pictóricos. Solo así se explica que su primera gran obra fuera rechazada por el entorno real prácticamente porque no se ajustaba su pintura a los cánones de la narración convencional. Posteriormente, cuando se traslada a Toledo, cambia el panorama porque la nueva realidad (sus mecenas eran religiosos como las instituciones donde habían de exhibirse sus cuadros) le obliga a ello. En síntesis, sus lecturas provocaron en él un cambio de temática.

Por lo que se refiere a Cerdá, es un hombre de letras muy importante, cercano a las estructuras de poder y que ejerce cargos públicos relacionados con el libro. Relanza la reedición de obras clásicas generalmente olvidadas y se preocupa de una cultura de élite. Pero su biblioteca fue extraordinaria y así lo atestiguan los que la conocieron.

54 Un punto de convergencia entre estos dos hombres se refiere al destino final de sus bibliotecas después de su muerte. Con Cerdá sabemos lo que ocurrió gracias a su testamento: muchos libros se legaron, otros se vendieron, otros se guardaron como pudieron en el domicilio por el que no se pagaba el alquiler por lo cual sufrieron amenazas de embargo. Con el Greco, sabemos que no realizó un inventario de sus libros y 
que fue su hijo el que años después del fallecimiento de su padre, lo hizo, aunque con algunas imprecisiones.

Después de tantas reflexiones sobre las bibliotecas privadas descritas a lo largo de este artículo, aún podríamos añadir una idea final. A la luz de las formas culturales del momento presente, puede parecer casi un anacronismo hablar de «bibliotecas privadas» cuando la tecnología de la comunicación pone en manos de cualquiera, a través de pequeños objetos, decenas y decenas de obras editadas en cualquier parte. Pero la versatilidad y mundialización de las formas comunicativas no pueden ser identificadas como la antesala de la desaparición de las formas convencionales de cultura. Afortunadamente, de vez en cuando, entre los pliegues de la literatura contemporánea, aparecen alusiones definitivas que nos invitan a reflexionar sobre estos asuntos. Precisamente, el literato argentino universal, Jorge Luis Borges, en El Aleph, nos describe en términos inequívocos algunos pasajes dramáticos referidos al pasado de la humanidad:

Arrasado el jardín, profanados los cálices y las aras, entraron a caballo los hunos en la biblioteca monástica y rompieron los libros incomprensibles y los vituperaron y los quemaron, acaso temerosos de que las letras encubrieran blasfemias contra su dios, que era una cimitarra de hierro (1997: 41).

Y unos párrafos más adelante, con palabras de supuesta aflicción, hace decir a su protagonista Aureliano, el coadjutor de Aquilea, lo que sigue:

Como todo poseedor de una biblioteca, Aureliano se sentía culpable de no conocerla

hasta el fin; esa controversia le permitió cumplir con muchos libros que parecían reprocharle su incuria (1997: 44).

Palabras clarividentes escritas por un hombre «que siempre había imaginado el Paraíso bajo la especie de una biblioteca».

\section{BIBLIOGRAFÍA}

BARTOLOMÉ Martínez Bernabé (1992), «Las bibliotecas públicas y la lectura», A. Escolano (dir.), Leer y escribir en España. Doscientos años de alfabetización, Madrid: Fundación Germán Sánchez Ruipérez.

BAYARD Pierre (2007), Comment parler des livres que l'on n'a pas lus ?, Paris: Les Éditions de Minuit. BoRgES Jorge Luis (1997), El Aleph, Madrid: Biblioteca Borges, Alianza Editorial.

Cossío Manuel Bartolomé (1983), El Greco, Madrid: Espasa-Calpe.

DEFOURNEAUX Marcelin (1973), Inquisición y censura de libros en la España del siglo XVIII, Madrid: Taurus.

Docampo Javier \& Riello José (2014), La Biblioteca del Greco, Madrid: Museo Nacional del Prado.

DOMERGUE Lucienne (1996), La censure des livres en Espagne à la fin de l'Ancien Régime, Madrid: Bibliothèque de la Casa de Velázquez, 13.

ENCISO RECIO Luis Miguel (2002), Barroco e Ilustración en las bibliotecas privadas españolas del siglo XVIII . Discurso leído el día 17 de marzo de 2002 en el acto de su recepción pública en la Real Academia 
de la Historia. Contestación a cargo de D. Vicente Palacio Atard, Madrid: Real Academia de la Historia.

GoNZÁLEZ Palencia Ángel (1948), Eruditos y Libreros del siglo XVIII. Estudios histórico-literarios, Madrid : C.S.I.C.

INFANTES Víctor, LóPEz François \& BOTREL Jean-François (dirs.) (2003), Historia de la edición y de la lectura en España, 1475-1914, Madrid: Fundación Germán Sánchez Ruipérez.

LAMARCA LANGA Genaro (1994), La cultura del libro en la época de la Ilustración. Valencia, 1740-1808, Valencia: Generalidad Valenciana, Diputación Provincial de Valencia.

López Delgado Juan Antonio (2008), La Biblioteca del Conde de Floridablanca, Murcia: Talleres de Artes Gráficas Novograf.

PÉREZ ReVerTe Arturo (2015), Hombres buenos, Madrid: Editorial Alfaguara.

SEMPERE Y GUARINOS Juan (6 tomos entre 1785-1789), Ensayo de una biblioteca española de los mejores escritores del reynado de Carlos III, Madrid: Imprenta Real.

SOUBEYRouX Jacques (1982), «La biblioteca de Campomanes: contexto cultural de un ilustrado», Actas del Séptimo Congreso de la Asociación Internacional de Hispanistas (997-1006), Roma: Bulsoni Editore.

URREIZTIETA José Luis (1985), Las tertulias de rebotica en España (siglos XVIII-XIX), Madrid: Ediciones Alonso.

ZARCo Del VALLE Manuel Remón \& SANCHO RAYón José (tomo 1, 1863 - tomo 2, 1867), Ensayo de una biblioteca española de libros raros y curiosos, tomo 1, formado con los apuntamientos de don Bartolomé José Gallardo, Madrid: Imprenta y Estereotipia de M. Rivadeneyra; tomo 2, formado con los apuntamientos de don Bartolomé José Gallardo; coordinados y aumentados por D. M. R. Zarco del Valle y D. J. Sancho Rayon, Madrid: Imprenta y Estereotipia de M. Rivadeneyra.

\section{NOTAS}

1. En torno a esta temática puede verse Infantes, López \& Botrel (2003), especialmente los tres artículos comprendidos en el capítulo 3 titulado genéricamente «Las bibliotecas», 114-141.

2. Sobre la censura de libros en España veánse las obras de Marcelin Defourneaux (1973) y de Lucienne Domergue (1996).

3. Aparte de obras de carácter generalista sobre este punto, también han proliferado investigaciones de carácter regional o local. Ver Lamarca Langa Genaro (1994).

4. Otra obra interesante no recogida en el estudio citado es la de López Delgado (2008).

5. Pudiera parecer que este fenómeno es solo un producto del pasado; sin embargo, estas situaciones se han mantenido a lo largo del tiempo, incluso en el presente. En una entrevista publicada por el diario El Mundo, en su edición del 25 de abril de 2015, con el conocido sociólogo y Catedrático de la Universidad Complutense de Madrid, Amando de Miguel, éste responde lo siguiente a una pregunta del periodista sobre sus tiempos de formación:

«-No tenía ningún libro en casa. Por eso mi obsesión por mi biblioteca; tengo 20.000 libros.

- ¿Y vende su biblioteca?

-Pero nadie me la compra. Nadie entiende que una biblioteca que tardas 40 o 50 años en formarla es la mejor biblioteca para estudiar la España del siglo xx».

6. Nació en 1776 en Campanario (Badajoz) y murió en Alcoy (Alicante) en 1852. 
7. Según Bartolomé Martínez (1992), la Biblioteca de las Cortes, creada en Cádiz, contó con un fondo de 10.000 volúmenes que, en gran parte, se trasladaron a Madrid una vez terminada la contienda.

8. «Caco, cuco, faquín, bibliopirata, / tenaza de los libros, chuzo, púa / de papeles, aparte lo ganzúa, / hurón, carcoma, polilleja, rata. / Uñilargo, garduño, garrapata, / para sacar los libros cabría, grúa / Argel de bibliotecas, gran falúa / armada en corso, haciendo cala y cata. / Empapas un archivo en la bragueta, / un Simancas te cabe en el bolsillo, / te pones por corbata una maleta. / Juegas del dos, del cinco y por tresillo; / y al fin te beberás como una sopa, / llenas de libros, África y Europa», en línea: <www.www.biblioteca.org.ar/libros/199.pdf>. Véase también Zarco del Valle Manuel Remón y Sancho Rayón José (1863 y 1867).

9. Los llamados «espacios Greco» por los organizadores, fueron los siguientes: Convento de Santo Domingo el Antiguo, Sacristía de la Catedral, Parroquia de Santo Tomé, Capilla de San José, Hospital Santuario de Nuestra Señora de la Caridad de Illescas y el Hospital Tavera-Fundación Casa Ducal de Medinaceli.

10. La Institución Libre de Enseñanza fue una entidad fundada en 1876 por Francisco Giner de los Ríos junto a un grupo de hombres liberales que aspiraban a reformar la sociedad española a través de la educación. En el sentir de muchos historiadores, las ideas y proyectos reales que llevaron a cabo desde su fundación han supuesto una de las mejores aportaciones acaecidas en la España contemporánea en el ámbito educativo.

11. «La exposición quiere reflexionar sobre la reputación de un pintor supuestamente místico, pero que no dejó escrita una línea sobre pintura religiosa, de un pretendido neoplatónico, que tenía libros de Aristóteles pero no de Platón, o del fundador de la escuela española de pintura, incapaz de hablar o escribir correctamente en la lengua de su coetáneo Cervantes» (Docampo, 2014: 11).

12. Ensayo de una biblioteca española de los mejores escritores del reynado de Carlos III, Madrid, Imprenta Real, 1785, 6 tomos (el último apareció en 1789). Por nuestra parte hemos manejado una edición facsímil a cargo de la Editorial Gredos, de Madrid, publicada en 1969, en tres volúmenes. Las páginas dedicadas a estudiar la obra de Cerdá y Rico, son las comprendidas entre la 173 y 185 del volumen primero que recoge los tomos 1 y 2 .

Juan Sempere y Guarinos (1754-1830) fue un notable político, jurista y bibliógrafo español que desempeñó diversos cargos relevantes en la administración pública de la época. Hombre de una cultura acreditada, los vaivenes políticos de esos años le llevan a sumarse a la causa de los afrancesados. Por este motivo hubo de exiliarse en diferentes ocasiones, sufriendo también penas de prisión.

13. Castalla, provincia de Alicante, fue la ciudad natal de Francisco Cerdá.

14. La palabra epiqueiya no está registrada en el Diccionario actual de la RAE. Se ha sustituido por epiqueya (del griego, equidad): «Interpretación moderada y prudente de la ley, según las circunstancias de tiempo, lugar y persona».

\section{RESÚMENES}

Dentro de un entorno genérico donde se analiza el significado de las bibliotecas privadas, sus modalidades a lo largo de la historia, la significación socio-cultural y otros aspectos, el artículo examina los casos de dos hombres ilustres en el mundo de la cultura, aunque adscritos a campos de especialización bien diferenciados. Uno de ellos es el pintor Dominico 
Theotocópuli (1541-1614) y el otro, perteneciente al siglo XVIII, es el escritor Francisco Cerdá y Rico. En el artículo, se pasa revista a las bibliotecas privadas de estos dos hombres, otorgando especial importancia a las influencias provenientes de las órbitas culturales del tiempo histórico en que vivieron. Uno de los elementos de análisis más utilizado a lo largo del trabajo, es el estudio de las disposiciones testamentarias redactadas por ambos personajes, hecho que permite conocer el verdadero fondo documental de sus colecciones.

Cet article analyse dans un contexte général la signification des bibliothèques privées, leurs modalités au cours de l'histoire, leur signification socio-culturelle ainsi que d'autres aspects éclairants, avant d'examiner le cas de deux hommes illustres dans le monde de la culture espagnole, bien qu'appartenant chacun à des domaines de spécialisation très différents. L'un d'eux est le célèbre peintre tolédan Domenikos Theotocopoulos (1541-1614) et l'autre, l'écrivain éclairé du xvIII ${ }^{\mathrm{e}}$ siècle, Francisco Cerdá y Rico. Les bibliothèques particulières de ces deux hommes sont passées en revue, en mettant en exergue les influences des productions culturelles de l'époque dans laquelle ils ont évolué. L'étude des dispositions testamentaires des deux personnages, un des éléments essentiel de l'analyse dans ce travail, permet de mieux connaître le véritable fonds documentaire de leurs collections respectives.

Within a generic framework focused on the analysis of private libraries meaning, the approaches throughout history, the socio-cultural significance as well as other aspects, this article studies the cases of two illustrious men, ascribed to different fields of specialization, in the cultural world. One of them is Domeniko Theotokópoulos (1541-1614) followed by 18th century writer Francisco Cerdá y Rico. This work presents an overview of both men private libraries and it attaches particular importance to the influences belonging to the cultural environment in which they evolved at the time. One of the most employed elements of the analysis is based on the testamentary dispositions written by both characters and provides a substantial information and a wider knowledge of the real content of their collections.

\section{ÍNDICE}

Mots-clés: Le Greco, Francisco Cerdá y Rico, Lumières, histoire des mentalités, testaments Palabras claves: El Greco, Francisco Cerdá y Rico, Ilustración, bibliotecas, historia de las mentalidades, testamentos

Keywords: El Greco, Francisco Cerdá y Rico, Enlightenment, history of mentalities, testaments

\section{AUTOR}

\section{VALÉRIE MOLERO}

Université Grenoble Alpes, ILCEA4 